\title{
INFLUÊNCIA DO PROCESSO DE COLHEITA NA INFESTAÇÃO DO MILHO (Zea mays L.) PELO BESOURO DA FARINHA (Tribolium castaneum Herbst) DURANTE O ARMAZENAMENTO ${ }^{1}$
}

\author{
Arienilmar Araújo Lopes da Silva', Lêda Rita D'Antonino Faroni', \\ José Helvécio Martins ${ }^{4}$ e Paulo Roberto Cecon ${ }^{5}$.
}

\begin{abstract}
RESUMO
Avaliou-se a influência dos danos físicos causados pelo processo de colheita sobre a infestação por Tribolium castaneum (Herbst) (Coleoptera: Tenebrionidae) no grão de milho armazenado. Duas variedades de milho, de consistência semi-dura e dura, foram colhidas manual e mecanicamente, com teores de umidade de 20,5 e 15,5\%; amostras desse material foram infestadas e, após, armazenadas. O desenvolvimento de $T$. castaneum foi avaliado por meio da taxa de crescimento populacional no período. Não houve diferenças significativas entre colheita manual e mecânica, entre as variedades semi-dura e dura; nem entre as umidades na colheita de 20,5 e $15,5 \%$, exceto na colheita mecanizada da variedade semi-dura que, com 20,5\% de umidade, apresentou maior percentual de grãos danificados por praga primária no campo.
\end{abstract}

Palavras-chave: milho, colheita, armazenamento, Tribolium castaneum

\section{INFLUENCE OF HARVEST PROCESS ON CORN (Zea mays L.) INFESTATION BY THE FLOUR BEETLE (Tribolium castaneum Herbst)}

\begin{abstract}
The effect of damages caused by harvest process on the development of the Tribolium castaneum (Herbst) (Coleoptera: Tenebrionidae) during storage was evaluated. Two varieties of corn, hard and semi-hard, were manually and mechanically harvested at 20.5 and $15.5 \%$ mean moisture contents (wet basis). The samples of this harvested corn were infested and stored. The development of $T$. castaneum was evaluated by intrinsic rate of population increase for that period. For development of $T$. castaneum, it was concluded that there were no significant differences between manual and mechanical harvesting, hard and semi-hard corn varieties and between 20.5 and $15.5 \%$ moisture contents. The exception being the case of mechanical harvest of semi-hard variety with $20.5 \%$ moisture, which presented a greater percentage of kernels damaged by field weevils.
\end{abstract}

Key words: maize, harvest, storage, Tribolium castaneum

\section{INTRODUÇÃO}

O Tribolium castaneum (Herbst) (Coleoptera: Tenebrionidae) é considerado uma praga de farinhas e outros produtos de cereais, mas pode sobreviver, também em grãos não danificados (White, 1982). É um inseto secundário que se desenvolve melhor nas massas de grãos com alto teor de impurezas e grãos quebrados, danificados pelo manuseio

\footnotetext{
${ }^{1}$ Parte da dissertação de mestrado apresentada pelo primeiro autor à UFV

${ }^{2}$ Estudante do Curso de Pós-Graduação de Engenharia Agrícola, DEA-UFV, Viçosa, MG, CEP 36570-000, fone (031) 899-1875, Fax (031) 899-2735, E-mail alsilva@alunos.ufv.br

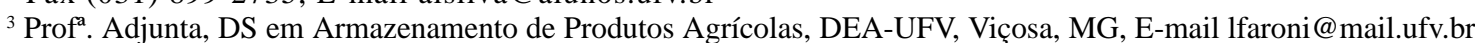

${ }^{4}$ Prof. Titular, PhD em Armazenamento de Produtos Agrícolas, DEA-UFV, Viçosa, MG

${ }^{5}$ Prof. Titular, DS em Matemática, DPI-UFV, Viçosa, MG. Fone (031) 899-2390, E-mail cecon@ dpi.ufv.br.
} 
mecanizado durante os processos de colheita, secagem e armazenamento ou, ainda, pode valer-se dos orifícios deixados pelos insetos primários, como os gorgulhos (Sokoloff, 1974). Por fim, para se justificar a importância da relação entre danos mecânicos e insetos secundários, ressalta-se que algumas larvas e ovos de Tribolium sobrevivem à própria moagem seca realizada pelas indústrias de alimentos, em que os grãos são triturados sucessivas vezes (Subramanyam \& Hagstrum, 1996). Pesquisas, como a de LiLi \& Arbogast (1991) têm mostrado o efeito significativo de grãos danificados no desenvolvimento de $T$. castaneum; entretanto, tais pesquisas foram realizadas com grãos artificialmente danificados e com níveis arbitrários de danos. Resta saber se os reais níveis de danos causados pelos processos normais de manuseio mecanizado também têm efeito significativo no desenvolvimento de $T$. castaneum durante a etapa de armazenamento, principalmente em se considerando as etapas de pré-limpeza e limpeza de grãos, que removem grande parte dos grãos danificados gerados nas etapas anteriores. Esta é a grande contribuição do presente trabalho, que buscou responder a esta questão para os danos causados exclusivamente pela etapa de colheita dos grãos de milho.

O teor de umidade é o principal fator que afeta a resistência de grãos a danos mecânicos durante o processo de colheita, além do histórico da cultura, da variedade e do estágio de maturação (Araújo, 1995). Segundo Brooker et al. (1992) o grão, na colheita mecanizada, está sujeito a impactos mecânicos que podem causar trincamento e quebra, e o teor de umidade que limita esses tipos de dano está em torno de $22 \%$, base úmida. Fatores adicionais que influenciam a ocorrência de danos no milho debulhado, são a velocidade do cilindro e a distância entre o cilindro e o côncavo nas colheitadeiras combinadas (Chowdhury \& Buchele, 1978; Hall \& Johnson, 1970; Mantovani, 1989).

Outro fator que afeta a resistência de grãos a danos mecânicos durante o processo de colheita, é a variedade. A característica de consistência ou dureza do grão, ou seja, sua resistência em ser quebrado e reduzido em partículas menores, pode ser diferente entre variedades (Hurburgh Jr., 1994). Segundo Hoseney \& Faubion (1992) a consistência do grão de milho influencia muitos fatores qualitativos, incluindo a resistência ao ataque de insetos e a quebra durante o manuseio, os danos ao amido produzido durante a moagem seca ou trituração e a potencialidade para produzir determinados produtos. De acordo com o padrão de classificação brasileiro (Brasil, 1982) um lote de milho pode ser classificado, quanto à consistência, como do Grupo Duro, do Grupo Mole, do Grupo Semi-duro ou do Grupo Misturado.

O objetivo deste trabalho foi avaliar a influência dos grãos danificados pelo processo de colheita do milho no desenvolvimento do $T$. castaneum durante o armazenamento e se buscou avaliar, principalmente, os reais níveis de danos causados pelo processo geral de colheita, comparando-se colheitas mecanizada e manual, diferentes teores de umidade de colheita, diferentes variedades de milho e interação entre esses fatores; além disso, buscou-se reproduzir as etapas, como pré-limpeza e limpeza, que afetam o teor de grãos danificados na massa, desde a colheita até o armazenamento.

\section{MATERIAL E MÉTODOS}

\section{Colheita}

Os grãos de milho (Zea mays L.) utilizados no presente estudo foram provenientes de duas lavouras, uma plantada com a cultivar silvestre denominada "palha-roxa" e a outra com a variedade comercial AG 122. O milho "palha-roxa” apresenta, predominantemente, grãos com consistência dura e o AG 122 apresenta grãos com consistência semi-dura. As lavouras foram formadas em uma área de aproximadamente $240 \mathrm{~m}^{2}$, em 12 fileiras de $24 \mathrm{~m}$ de comprimento, espaçamento entre linhas de $0,9 \mathrm{~m}$ e densidade de plantio de 25 plantas $/ \mathrm{m}^{2}$. A colheita mecanizada foi realizada utilizando-se uma colheitadeira combinada, modelo Lavrale 300, com plataforma de colheita para duas linhas. A velocidade do cilindro debulhador, não regulável neste modelo de colheitadeira, foi de $485 \mathrm{rpm}$ e o diâmetro do mesmo igual a $40 \mathrm{~cm}$. Simultaneamente, foram realizadas colheitas manuais para serem comparadas com as mecanizadas. As colheitas manual e mecanizada foram realizadas quando o milho das duas lavouras apresentou teor de umidade médio de $20,5 \%$ e $15,5 \%$, base úmida.

\section{Percentual de grãos infestados}

Os danos causados por insetos primários ainda no campo, foram avaliados para que se pudesse estudar separadamente o efeito desses danos e o efeito dos danos causados pela colheita, evitando-se erro nas conclusões finais. Assim, o objetivo desta avaliação é informar o quanto cada tratamento está danificado por insetos e não o por que de estar danificado. Embora as espigas muito infestadas normalmente sejam excluídas durante a debulha manual, tomou-se o cuidado, para efeito comparativo, de evitar seleção neste trabalho, porque isto não ocorre na colheitadeira. Para o teste, as amostras foram umedecidas por 6 minutos em solução de iodo a $4 \%$ para os grãos exibirem nitidamente os danos causados por pragas primárias, quer tenham sido os grãos danificados por uma única espécie de inseto, quer por várias. $\mathrm{O}$ resultado foi expresso em percentagem média de grãos infestados.

\section{Armazenamento e avaliação do desenvolvimento do T. castaneum}

Após a colheita, o milho passou por processo manual de pré-limpeza com peneiras e depois foi expurgado para eliminação das pragas de campo; em seguida, realizou-se secagem natural, à sombra, até o milho atingir o teor de umidade de 13\%; assim, evitaram-se os danos que poderiam ser causados por uma secagem artificial. Após a secagem, o milho passou pelo processo manual de limpeza, utilizando-se peneiras de crivo circular de 4,76mm de diâmetro, conforme as normas brasileiras (BRASIL, 1982); depois, amostras de 250g, representativas de cada combinação variedade-método de colheita-teor de umidade (tratamentos) foram infestadas com 40 insetos adultos da espécie T. castaneum. Todos os tratamentos foram acondicionados em uma câmara de desenvolvimento biológico, mantida a temperatura de $32 \pm 2^{\circ} \mathrm{C}$ e umidade relativa de $65 \pm 5 \%$ que, segundo Gray, citado por Pedersen (1992) constituem as condições ideais para o inseto. Escolheu-se o período de armazenamento de 47 dias a fim de possibilitar a ocorrência do ciclo de vida de uma geração do inseto. Decorrido esse tempo, cada amostra infestada foi peneirada para se proceder à primeira contagem dos insetos e, logo em seguida, submetida ao funil-de-Barlesi, para se efetuar a segunda contagem. A soma das duas contagens totalizou o número final de insetos vivos depois do armazenamento. A taxa de crescimento populacional 
foi determinada conforme a equação citada por Pedersen (1992):

$$
r=\left(\ln N_{t}-\ln N_{0}\right) / t
$$

$r$ - taxa de crescimento

$t$ - tempo de infestação em dias

$N_{0}$ - número de insetos vivos no tempo zero

$N_{t}$ - número de insetos vivos no tempo $t$

Além da consistência do grão, poderia haver diferenças nutricionais entre as variedades capazes de levar a diferentes taxas de crescimento populacional do inseto. Para se verificar essa possibilidade, colocou-se o $T$. castaneum para desenvolvimento em amostras totalmente trituradas, o que eliminou o fator consistência.

\section{Delineamento experimental e análise dos dados}

Utilizou-se o delineamento inteiramente casualizado, em esquema fatorial $2^{\prime} 2^{\prime} 2$, ou seja, dois tipos de colheita, manual e mecanizada, duas variedades de milho, uma com grãos de consistência dura e outra com grãos de consistência semi-dura e dois teores de umidade na época da colheita, 20,5 e 15,5\%, com quatro repetições. Os dados obtidos em percentagem foram avaliados quanto à homogeneidade, por meio dos testes de Cochran \& Bartlett e quanto à normalidade, por meio do teste de Lilliefors. Quando necessário, os dados foram transformados utilizando-se a Equação (2). Os dados foram interpretados por meio de análise de variância e as médias foram comparadas utilizando-se o teste de Tukey, a 5\% de probabilidade.

$$
y=\operatorname{arcsen} \sqrt{x / 100}
$$

\section{RESULTADOS E DISCUSSÃO}

\section{Percentual de grãos infestados}

Os dados obtidos por meio deste teste são muito importantes para grãos como milho, sorgo, trigo e feijão, freqüentemente infestados por insetos primários ainda no campo. Os grãos infestados já favorecem o desenvolvimento do T. castaneum mas, por estarem mais frágeis, podem ser danificados com maior intensidade pela colheita mecanizada e favorecer ainda mais o desenvolvimento do inseto. Observa-se, nas Tabelas 1 e 2, que no material colhido não houve diferença significativa entre as colheitas manual e mecânica para o percentual de grãos infestados, em qualquer combinação de variedade e teor de umidade na colheita.

Normalmente, quanto mais seco estiver o milho na época da colheita, ou seja, quanto mais tardia for a colheita, maior será o percentual de grãos infestados (Brooker et al.,1992).

Tabela 1. Valores médios* de percentual de grãos infestados de acordo com a variedade, umidade na época da colheita e

\begin{tabular}{|c|c|c|c|c|}
\hline \multirow{3}{*}{ Colheita } & \multicolumn{2}{|c|}{ Variedade Semi-dura } & \multicolumn{2}{|c|}{ Variedade Dura } \\
\hline & \multicolumn{2}{|c|}{ Umidade na Colheita } & \multicolumn{2}{|c|}{ Umidade na Colheita } \\
\hline & $20,5 \%$ & $15,5 \%$ & $20,5 \%$ & $15,5 \%$ \\
\hline Mecânica & 3,64 a $\mathrm{A}$ & 2,13 a B & 0,07 a B & 1,41 a $\mathrm{A}$ \\
\hline Manual & 3,20 a $\mathrm{A}$ & 3,14 a A & 1,11 a $\mathrm{A}$ & 0,94 a $\mathrm{A}$ \\
\hline
\end{tabular}
procedimento de colheita

*As médias seguidas de uma mesma letra maiúscula nas linhas e minúscula nas colunas, para cada variedade, não diferem pelo teste de Tukey, a 5\% de probabilidade
Observa-se, na Tabela 1, relativa às umidades de colheita, que não ocorreu esta tendência, fato que só se explicaria pela ecologia de ataque do inseto primário no campo (Brewster \& Allen, 1997) o que está fora da competência deste trabalho. Quanto às variedades, observa-se que a semi-dura foi a mais atacada pelos insetos primários ainda no campo (Tabela 2).

Tabela 2. Valores médios* de percentual de grãos infestados de acordo com a variedade, umidade na época da colheita e

\begin{tabular}{|c|c|c|c|c|}
\hline \multirow[t]{2}{*}{ Colheita } & \multicolumn{2}{|c|}{$\begin{array}{c}\text { Umidade na Colheita } 20,5 \% \\
\text { Variedade }\end{array}$} & \multicolumn{2}{|c|}{$\begin{array}{c}\text { Umidade na Colheita } 15,5 \% \\
\text { Variedade }\end{array}$} \\
\hline & Semi-dura & Dura & Semi-dura & Dura \\
\hline Mecânica & 3,64 a A & 0,07 a B & 2,13 a $\mathrm{A}$ & 1,41 a $\mathrm{A}$ \\
\hline Manual & 3,20 a A & 1,11 a $\mathrm{B}$ & 3,14 a A & 0,94 a B \\
\hline
\end{tabular}
procedimento de colheita

*As médias seguidas de uma mesma letra maiúscula nas linhas e minúscula nas colunas, para cada umidade, não diferem pelo teste de Tukey, a 5\% de probabilidade

\section{Avaliação do desenvolvimento do $T$. castaneum}

A análise de variância da taxa de crescimento populacional do T. castaneum nas amostras de milho triturado, Tabela 3 , demonstra que não ocorreu diferença nutricional entre as variedades capaz de causar uma diferença significativa na taxa. Assim, pode-se afirmar que não ocorreu diferença nutricional significativa entre as variedades e qualquer diferença na taxa de crescimento entre elas, dentro dos tratamentos, é devida ao efeito da colheita.

Tabela 3. Resumo da análise de variância da taxa de crescimento do $T$. castaneum em amostras de grãos triturados

\begin{tabular}{lcc}
\hline \multicolumn{1}{c}{ Fontes de Variação } & G.L. & Quadrados Médios \\
\hline Grãos triturados & 1 & 0,00001 n.s. \\
Resíduo & 6 & 0,00006 \\
\hline C.V. (\%) & - & 47,45 \\
\hline n.s. Não significativo a 5\% de probabilidade, pelo teste F &
\end{tabular}

Quanto ao efeito da umidade na época da colheita sobre a taxa de crescimento, Tabela 4, verifica-se que a variedade semidura, colhida mecanicamente, com teor de umidade mais elevado, apresentou condições mais favoráveis ao desenvolvimento do T. castaneum. Quanto ao efeito das variedades, Tabela 5 , não houve diferença entre elas com a umidade, na época da colheita, de $15,5 \%$, mas com a de $20,5 \%$, a variedade semi-dura, colhida mecanicamente, apresentou maior taxa de crescimento; em relação ao procedimento de colheita não houve, de modo geral, diferença entre colheitas manuais e mecânicas, exceto para a variedade semi-dura colhida com $20,5 \%$ de umidade. Nesta combinação, o T. castaneum apresentou taxa de crescimento maior no milho colhido mecanicamente.

Tabela 4. Valores médios* da taxa de crescimento do T. castaneum, de acordo com a variedade, a umidade na época da colheita e o procedimento de colheita**

\begin{tabular}{lcclccc}
\hline \multirow{2}{*}{ Colheita } & \multicolumn{2}{c}{ Variedade Semi-dura } & & \multicolumn{2}{c}{ Variedade Dura } \\
\cline { 2 - 3 } \cline { 5 - 6 } & \multicolumn{2}{c}{ Umidades na Colheita } & & \multicolumn{2}{c}{ Umidades na Colheita } \\
\hline \multirow{2}{*}{ Mecânica } & $20,5 \%$ & $15,5 \%$ & & $20,5 \%$ & $15,5 \%$ \\
Manual & $-7,5$ a A & $-2,2$ a B & & $-4,7$ a A & $-3,0$ a A \\
\cline { 6 - 7 } & $-3,0$ & a A & & $-6,0$ a A & $-3,2$ a A
\end{tabular}

*As médias seguidas de uma mesma letra maiúscula nas linhas e minúscula nas colunas, para cada variedade, não diferem pelo teste de Tukey, a $5 \%$ de probabilidade *** Valores multiplicados por 103 
Tabela 5. Valores médios* da taxa de crescimento do T. castaneum, de acordo com a variedade, a umidade na época da colheita e o procedimento de colheita**

\begin{tabular}{|c|c|c|c|c|}
\hline \multirow{3}{*}{ Colheita } & \multicolumn{2}{|c|}{ Umidade na Colheita $20,5 \%$} & \multicolumn{2}{|c|}{ Umidade na Colheita $15,5 \%$} \\
\hline & \multicolumn{2}{|c|}{ Variedades } & \multicolumn{2}{|c|}{ Variedades } \\
\hline & Semi-dura & Dura & Semi-dura & Dura \\
\hline Mecânica & 0,5 a $\mathrm{A}$ & $-4,7$ a B & $-2,2$ a $\mathrm{A}$ & $-3,0$ a $A$ \\
\hline Manual & $-0,7$ b A & $-6,0$ a $A$ & $-3,0$ a $A$ & $-3,2$ a $A$ \\
\hline
\end{tabular}

*As médias seguidas de uma mesma letra maiúscula nas linhas e minúscula nas colunas, para cada umidade, não diferem pelo teste de Tukey, a $5 \%$ de probabilidade

** Valores multiplicados por 103

Observando-se simultaneamente os resultados da taxa de crescimento populacional do $T$. castaneum e os resultados de percentual de grãos infestados, verifica-se que não houve diferença no desenvolvimento da praga entre o milho colhido manualmente e o colhido mecanicamente, quando entre eles também não houve diferença no percentual de grãos infestados; verifica-se, também, que não houve diferença no desenvolvimento da praga para um mesmo método de colheita, manual ou mecânico, mesmo quando nele ocorreu diferença no percentual de grãos infestados; portanto, foi preciso que danos por insetos primários e pela colheita mecanizada ocorressem em conjunto para que a massa de grãos apresentasse menor resistência à infestação pelo T. castaneum.

Observou-se, ainda, que a maior taxa de crescimento obtida entre as combinações de tratamento deste trabalho foi de 0,0105 insetos. dia ${ }^{-1}$ em 47 dias de armazenamento. Leslie \& Park, citados por Pedersen (1992) encontraram uma taxa de 0,0980 insetos. dia $^{-1}$ para 47 dias em condições ótimas; portanto, os danos físicos causados apenas pela colheita mecânica propiciaram uma taxa de crescimento do T. castaneum que representa $10 \%$ de sua máxima taxa possível.

\section{CONCLUSÕES}

A taxa de crescimento populacional do T. castaneum não foi significativamente diferente entre as colheitas manual e mecânica, entre as variedades semi-dura e dura, nem entre as umidades na colheita de 20,5 e $15,5 \%$, exceto para o tratamento com colheita mecanizada da variedade semi-dura, com $20,5 \%$ de umidade, por causa da influência do percentual de grãos infestados; portanto, os danos causados pelo processo de colheita, para a faixa de teor de umidade e variedades de milho estudadas neste trabalho, não têm efeito no desenvolvimento de $T$. castaneum durante o armazenamento, mas a colheita mecanizada de variedades de menor dureza de grãos e já danificados por insetos primários no campo, pode favorecer a infestação por T. castaneum durante o armazenamento.

\section{REFERÊNCIAS BIBLIOGRÁFICAS}

ARAÚJO, R.F. Efeito da colheita mecanizada nas perdas quantitativas e qualitativas de sementes de milho ( $\mathrm{Zea}$ mays, L.). Viçosa, MG: UFV, 1995. 103p. Tese Doutorado

BRASIL. Ministério da Agricultura. Secretaria Nacional de Abastecimento. Comissão Técnica de Normas e Padrões. Normas de identidade, qualidade, embalagem e apresentação do milho. Brasília, DF, 1982. 12 p.

BREWSTER, R. \& ALLEN, J.D. Spatiotemporal insect model. Environmental Entomology, Lanham, MD, v.26, n.3, p.475-48, 1997.

BROOKER, D.B.; BAKKER-ARKEMA, F.W.; HALL, C.H. Drying and storage of grains and oilseeds. Westport: AVI, 1992. $450 \mathrm{p}$.

CHOWDHURY, M.H.; BUCHELE W.F. The nature of corn kernel damage inflicted in the shelling crescent of grain combines. Transactions of the ASAE, St. Joseph, v.21, n.3, p.610-614, 1978.

HALL, G.E.; JOHNSON, W.H. Corn kernel crackcage induced by mechanical shelling. Transactions of the ASAE, St. Joseph, v.13, n.1, p.51-55, 1970.

HOSENEY, R.C.; FAUBION, J.M. Physical properties of cereal grains. In: Storage of cereal grains and their products. St. Paul: American Association of Cereal Chemists, Inc, 1992. p.1-39.

HURBURGH Jr., C.R. Corn quality patterns in U.S. markets. Applied Engineering in Agriculture, Iowa, v.10, n.4, p.515 - 521, 1994.

LI LI; ARBOGAST, R.T. The effect of grain breakage on fecundity, development, survival, and population increase in maize of Tribolium castaneum (Herbst) (Coleoptera: Tenebrionidae). Journal of Stored Product Research, Oxford, U.K., v.27, n.2, p.87-94, 1991.

MANTOVANI, E.C. A colheita mecânica do milho. In: FUNDAÇÃO CARGIL. Colheita mecânica, secagem e armazenamento do milho. Campinas, 1989. 24p. (Série Técnica, 2).

PEDERSEN, J.R. Insects: indentification, damage and detection. In: Storage of cereal grains and their products. St. Paul: American Association of Cereal Chemists, Inc, 1992. p.435-491.

SOKOLOFF, A. The biology of Tribolium Oxford: Oxford University Press, v.2. 1974. 610p.

SUBRAMANYAM, B.; HAGSTRUM, D. Integrated management of insects in stored products. New York: Marcel Dekker, 1996. 954p.

WHITE, G.G. The effect of grain damage on development in wheat of Tribolium castaneum (Herbst) (Coleoptera: Tenebrionidae). Journal of Stored Product Research, Oxford, U.K., v.187, p.115-119, 1982. 